\title{
The Prevalence of Founder Mutations among Individuals from Families with Familial Pancreatic Cancer Syndrome
}

\author{
Marcin R. Lener, PhD \\ Aniruddh Kashyap, MD, PhD \\ Wojciech Kluźniak, MSc \\ Cezary Cybulski, MD, PhD \\ Agnieszka Soluch, MSC \\ Sandra Pietrzak, MSC \\ Tomasz Huzarski, MD, PhD \\ Jacek Gronwald, MD, PhD \\ Jan Lubiński, MD, PhD
}

Department of Genetics and Pathology, International Hereditary Cancer Center, Pomeranian Medical University in Szczecin, Szczecin, Poland

\begin{abstract}
Purpose
Familial pancreatic cancer describes families with at least two first-degree relatives with pancreatic cancer that do not fulfil the criteria of other inherited tumor syndromes with increased risks of pancreatic cancer. Although much has been learned regarding the aggregation of pancreatic cancer in some families, the genetic basis for this familial aggregation is poorly understood. This study evaluated the prevalence of 10 Polish founder mutations in four genes among individuals from families with diagnosed familial pancreatic cancer syndrome and assessed their possible association with the familial pancreatic cancer (FPC) risk in Poland.
\end{abstract}

\section{Materials and Methods}

In this study, 400 FPC individuals and 4,000 control subjects were genotyped for founder mutations in BRCA1 (5382insC, 4153delA, C61G), CHEK2 (1100delC, IVS2+1G>A, del5395, I157T), NBS1 (657del5), and PALB2 (509_510delGA, 172_175delTTGT) genes.

\section{Results}

A statistically significant association was observed between the 172_175delTTGT mutation of the PALB2 gene and an increased risk of FPC syndrome (odds ratio [OR], 10.05; $\mathrm{p}=0.048$ ). In addition, an increased risk of cancer was observed in the FPC family members with a BRCA1 mutation (OR, 6.72; $p=0.006)$. Novel associations were found between the FPC family members with cancer and CHEK2 mutations (OR, 2.26; $p=0.008$ ) with a noticeable contribution of the missense variant, I157T of CHEK2 (OR, 2.17; $p=0.026$ ).

\section{Conclusion}

The founder mutations in the genes, BRCA1, PALB2, and CHEK2, cause a small percentage of familial pancreatic cancer syndrome in the Polish population. Following confirmation in larger studies, these mutations can be added to the panel of genes to be tested in families with a diagnosis of FPC syndrome.
Correspondence: Marcin R. Lener, $\mathrm{PhD}$ Department of Genetics and Pathology, International Hereditary Cancer Center, Pomeranian Medical University in Szczecin, Połabska 4, 70-115 Szczecin, Poland Tel: 48-91-466-1532

Fax: 48-91-466-1533

E-mail: marcinlener@poczta.onet.pl

Received May 25, 2016

Accepted July 18, 2016

Published Online July 28, 2016

\section{Key words}

Familial pancreatic cancer, Founder mutations, CHEK2 gene, Cancer risk

\section{Introduction}

Studies over the past four decades have shown that 3.9\%$16 \%$ of patients with pancreatic cancer $(\mathrm{PaCa})$ have a family history of the disease, which is referred to as familial pancreatic cancer (FPC) [1]. FPC describes families with at least two first-degree relatives with confirmed exocrine $\mathrm{PaCa}$ that do not fulfil the criteria of other inherited tumor syndromes with increased risks of $\mathrm{PaCa}$, such as Peutz-Jeghers syndrome, hereditary pancreatitis, and hereditary breast and ovarian cancer. The first studies to explore what is now referred to as FPC were case reports of families in which there were multiple cases of PaCa. In 1973, MacDermott and Kramer [2] described a family, in which PaCa developed in four out of the six siblings. 
A small fraction of this aggregation can be accounted for inherited cancer syndromes, including familial atypical multiple-mole melanoma (FAMM), Peutz-Jeghers syndrome, hereditary breast-ovarian cancer (HBOC), hereditary pancreatitis (HP), and hereditary nonpolyposis colorectal cancer (HNPCC). These syndromes arise as a result of germline mutations in the CDKN2A (FAMM), STK11 (Peutz-Jeghers syndrome), BRCA1, BRCA2, ATM (HBOC), PRSS1 (HP), MLH1, and MSH2 (HNPCC) genes [3]. In addition, heredity plays an important role in certain patients with apparently sporadic PaCa. Many patients with PaCas caused by a germline mutation in a cancer-causing gene do not have a pedigree suggestive of a familial cancer syndrome [1]. Although much has been learned over the past few decades regarding the aggregation of $\mathrm{PaCa}$ in some families, the genetic basis for most of this familial aggregation is still poorly understood.

Ten founder mutations in four cancer predisposing genes have been identified in Poland [4-6]. These include three founder mutations in BRCA1 (5382insC, 4153delA, and C61G), four in CHEK2 (1100delC, IVS2+1G >A, del5395, and

Table 1. Characteristics of the FPC individuals

\begin{tabular}{lc}
\hline Characteristic & No. \\
\hline All FPC cases & 400 \\
Healthy & 295 \\
FPC individuals with cancer & 105 \\
Age of onset (yr) & \\
$<50$ & 202 (female 152, male 50) \\
\hline 50 & $1921-1968$ \\
\hline Birth year & $49.44(19-91)$ \\
\hline Age at sample, mean (range, yr) & $46.11(19-80)$ \\
Healthy FPC individuals & $59.13(30-91)$ \\
\hline FPC cases with cancer & \\
Cancer site among cancer & \\
FPC cases & 36 \\
Pancreas & 28 \\
Breast & 9 \\
Nipple & 7 \\
\hline Uterus & 5 \\
Ovary & 4 \\
Large intestine & 1 \\
Small intestine & 2 \\
Kidney & 2 \\
Melanoma & 2 \\
\hline Thyroid & 1 \\
Cheek & \\
\hline Cancer site unknown & \\
\hline
\end{tabular}

FPC, familial pancreatic cancer.
I157T), one variant allele in NBS1 (657del5), and two in PALB2 (509_510delGA and 172_175delTTGT) [4-6]. The results of our previous case/control studies showed that these mutations in BRCA1, CHEK2, NBS1, and PALB2 are associated with the cancer risk at different sites of origin [4-12]. A recent study evaluated the prevalence of these founder mutations among sporadic PaCa patients and showed that the risk of sporadic $\mathrm{PaCa}$ is associated with the Slavic founder mutation of NBS1 657del5 (odds ratio [OR], 3.80; $p=0.002$ ) [13]. A hereditary predisposition to different cancers, which is characteristic of the aforementioned genes, suggests that there could be a potential link between Polish founder mutations and a predisposition to FPC.

Therefore, the aim of this study was to establish the prevalence of ten Polish founder mutations in BRCA1, CHEK2, NBS1, and PALB2 among individuals from families with familial PaCa syndrome and to assess their possible association with the FPC risk in Poland.

A total of 400 individuals from FPC syndrome families were genotyped and the frequencies of the founder mutations were compared with a set of healthy control subjects representative of the Polish population.

\section{Materials and Methods}

\section{Patients}

The recruitment of individuals for this study was conducted between 2002 and 2014. The majority (80\%) were patients of our center, living in north-western Poland, as well as in other cities of the country: Białystok, Kraków, Lódź, Olsztyn, Opole, Rzeszów, Świdnica, Zielona Góra, Kielce. The study involved 400 probands from families with a diagnosis of FPC syndrome, who were either healthy individuals $(\mathrm{n}=295)$ or FPC patients with cancer $(\mathrm{n}=105)$. Table 1 lists the characteristics of the individuals included in the study. Each of the 400 study participants came from a family, in which there were two or more cases of $\mathrm{PaCa}$ among the first-degree relatives. All study participants with cancer had a histopathologically confirmed diagnosis of cancer. The mean age of the participants enrolled in this study was 49.44 years (range, 19 to 91 years). A family history of cancer was taken either by the construction of a family tree or the completion of a standardized questionnaire. This study was conducted in accordance with the Declaration of Helsinki and all participants signed an informed consent document prior to donating the blood samples. Furthermore, this study was approved by the Ethics Committee of the Pomeranian Medical University in Szczecin, Poland. 


\section{Population controls}

Three control groups were combined. The first consisted of 2,000 newborn children from 10 hospitals throughout Poland (Szczecin, Białystok, Gorzów, Katowice, Wrocław, Poznań, Opole, Lódź, and Rzeszów) collected between 2003 and 2004. Samples of cord blood from unselected infants were forwarded to the study center in Szczecin. The second group was taken from adult patient lists of three family doctors practicing in the Szczecin region. A total of 1,000 controls were selected at random from the patient lists of these family doctors. The third group consisted of 1,000 adults from Szczecin who submitted blood for paternity testing. A sample of DNA was forwarded to the reference laboratory without any identifying information. To ensure comparability of the control groups, the allele frequencies of the 10 alleles was computed separately for the adult and neonatal control groups and compared to determine if there were any differences in allele frequencies.

\section{Genotyping}

DNA was isolated from 5 to $10 \mathrm{~mL}$ samples of peripheral blood. Ten founder mutations in the BRCA1, CHEK2, NBS1, and PALB2 genes were genotyped, as described previously $[4,6,9]$. Briefly, BRCA1 mutations, 4153delA and 5382insC were detected using the allele-specific oligonucleotide polymerase chain reaction (PCR), and $\mathrm{C} 61 \mathrm{G}$ was detected using the restriction fragment length polymorphism PCR. The CHEK2 del5395 was detected using a multiplex PCR reaction. The IVS2+1G $>A$ and I157T variants in CHEK2 were detected using restriction fragment length polymorphism PCR analysis, and the $1100 \mathrm{delC}$ mutation was analyzed using allelespecific oligonucleotide PCR. The NBS1 mutation was tested using allele-specific oligonucleotide PCR. The two recurrent truncating mutations of PALB2 (509_510delGA and 172 175delTTGT) were detected using a TaqMan assay (Life Technologies, Carlsbad, CA) using a LightCycler 480 RealTime PCR System (Roche Life Science, Mannheim, Germany). Sanger direct sequencing was undertaken to confirm the presence of mutations, using a BigDye Terminator v3.1 Cycle Sequencing Kit (Life Technologies), according to the manufacturer's protocol. All ten mutations were analyzed successfully in 398 of the 400 FPC cases (99.5\%). The two that failed to be analyzed due to the poor quality of DNA were discarded from statistical analysis.

\section{Statistical analysis}

The prevalence of all mutant alleles in the cases and controls were compared. The ORs were generated from twoby-two tables and the statistical significance was assessed using a chi-square or Fisher exact test with a Yates correction. The ORs were used as the estimates of the relative risk.

\section{Results}

A founder mutation in one of the four genes studied was observed in 44 out of 398 FPC cases $(11.06 \%)$ and in 283 out of 4,000 controls $(7.08 \%)(\mathrm{p}=0.011 ; \mathrm{OR}, 1.56 ; 95 \%$ confidence interval, 1.12 to 2.18 ). Table 2 provides details of the prevalence of founder mutations studied among individuals from FPC families and in the population control group. In the group of all FPC individuals, the largest and statistically significant difference compared to the population control group was observed for PALB2 172_175delTTGT (0.5\%; OR, 10.05; $\mathrm{p}=0.048$ ). When the genotyping results were classified according to the health status of the probands, statistically significant differences were observed for the BRCA1, PALB2 and CHEK2 genes only in the group of FPC cases with cancer. Two (5382insC, C61G) of the three Polish founder BRCA1 mutations were detected in three of the 105 FPC cases with cancer $(2.86 \%)(\mathrm{OR}, 6.72 ; \mathrm{p}=0.006)$ compared to 17 of the 4,000 controls $(0.42 \%)$. PALB2 mutations were observed in two of the 105 FPC cases with cancer $(1.90 \%)$ (OR, 9.52; $\mathrm{p}=0.014)$ compared to eight of the 4,000 controls $(0.20 \%)$. CHEK2 mutations (all four mutations combined) were detected in 14 of the 105 FPC cases with cancer $(13.33 \%)$ (OR, 2.26; $\mathrm{p}=0.008$ ) compared to 236 of the 4,000 controls (5.9\%). The CHEK2 I157T missense mutation contributed the largest and was present in 11 of the $105 \mathrm{FPC}$ cases with cancer (OR, 2.17; $\mathrm{p}=0.026$ ) compared to 193 of the 4,000 controls. A single NBS1 mutation (657del5) was detected in three of the 389 unselected FPC cases $(0.75 \%)$ : two healthy FPC probands $(0.68 \%)$, and one of the 105 FPC cases with cancer $(0.95 \%)$, compared to 22 of the 4,000 controls $(0.55 \%)$, but none of the associations were statistically significant.

\section{Discussion}

This study observed a significant correlation between the prevalence of the Polish founder mutation 172_175delTTGT of PALB2 gene and the FPC. In addition, an increased incidence of changes was observed in genes BRCA1 (three founder mutation combined: $\mathrm{p}=0.006 ; \mathrm{OR}, 6.72$ ) and CHEK2 (four CHEK2 mutations combined: $\mathrm{p}=0.008$; OR, 2.26), particularly the CHEK2 I157T mutation ( $\mathrm{p}=0.03$; OR, 2.17) among the cancer-affected individuals from the FPC syn- 


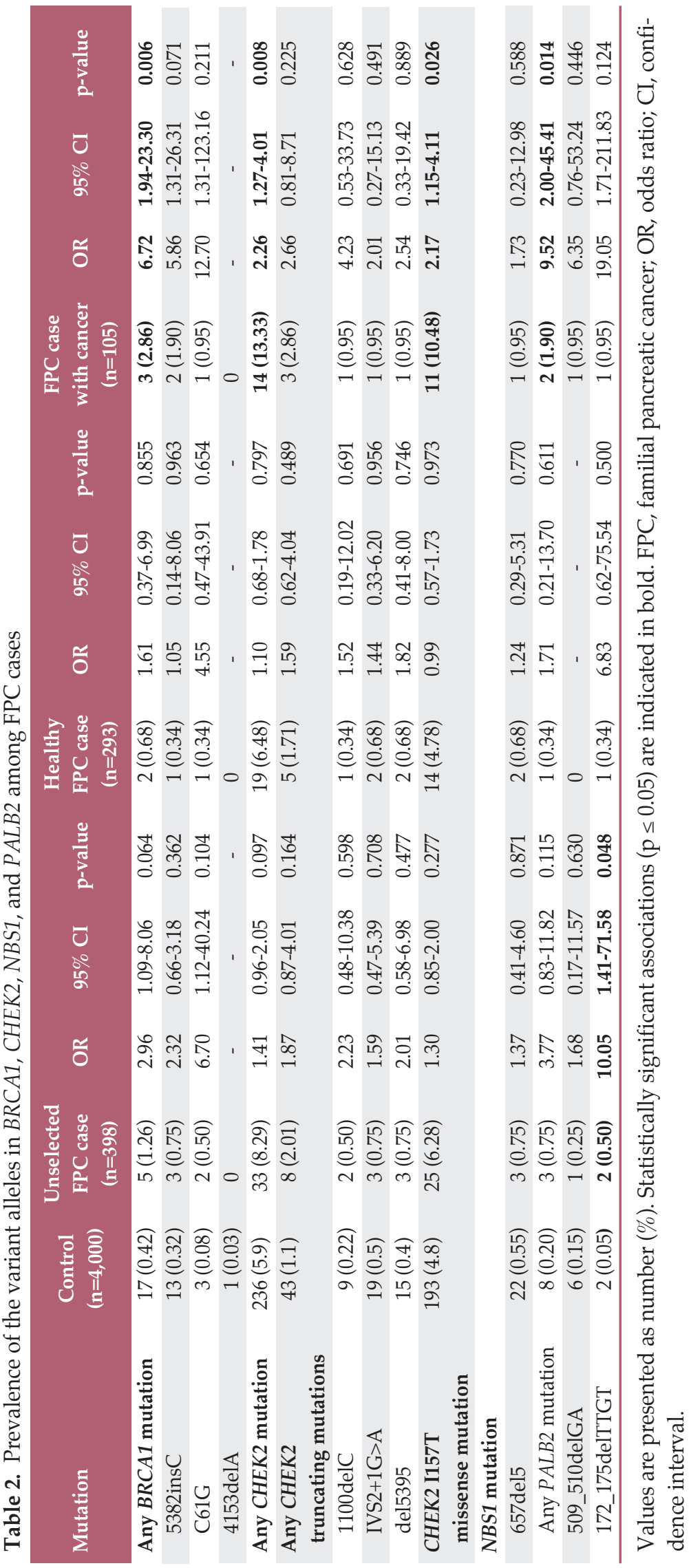


drome families. The fact that BRCA1 and PALB2 mutations might be causative of FPC in a small subset of families is relatively new [14-16]. These results confirm this correlation in Polish families with FPC syndrome. Furthermore, the results are consistent with the observations that PALB2 and BRCA1 mutations are reported in FPC, especially in the families with a history of breast cancer [14,15]. Breast cancer was also observed among the first degree relatives of one of the PALB2 172_175delTTGT and one of the BRCA1 5382insC mutation carriers from FPC.

The most valuable observation of the present study is the increased risk of FPC among carriers of CHEK2 mutations, particularly the CHEK2 I157T missense variant. CHEK2 is a human homologue of the yeast Cds1 and Rad53 genes, which encodes the cell cycle checkpoint kinase. CHEK2 is activated by ATM dependent phosphorylation in response to double strand DNA breaks $[17,18]$. Activated CHEK2 activates $p 53$, which triggers cell cycle arrest at G1 or apoptosis $[19,20]$. Therefore, CHEK2 plays an important role in the network of cell cycle regulation and DNA damage repair, which are crucial processes in preventing cancer development. Four founder alleles of CHEK2 are present in Poland; three of these result in a truncated CHEK2 protein (1100delC, IVS2+1G $>A$ and del5395) and the fourth (I157T) is a missense substitution of an isoleucine by a threonine in exon 3 [9]. The feature of the founder mutations in the CHEK2 gene is the multiorgan cancer risk among carriers [8]. Positive associations with protein-truncating alleles in the CHEK2 gene are observed for cancers of the prostate and thyroid. The large germline deletion in CHEK2 is associated with an increased risk of prostate cancer [9]. The missense variant, I157T, is associated with an increased risk of colon, kidney, prostate, thyroid, and stomach cancers $[8,11]$. In light of existing research, it can be assumed that CHEK2 gene mutations are more specific to a certain percentage of cancers of the gastrointestinal tract. In a study conducted at our center including 463 individuals, it has been shown that the I157T variant of CHEK2 increases the risk of colorectal cancer among mismatch repair-negative HNPCC/HNPCC-related families from Poland (OR, 2.1; $\mathrm{p}=0.0004)$ [21]. Polish founder mutations in the CHEK2 gene were also observed in 57 out of 658 unselected patients with gastric cancer $(8.7 \%)$ compared to 480 out of 8,302 controls (5.8\%) (OR, 1.6; $\mathrm{p}=0.004)$ [11]. Overall, it can be concluded that FPC is another malignant tumor from the spectrum of digestive system cancers associated with mutations of the CHEK2 gene. The results of a previous study conducted among $383 \mathrm{PaCa}$ cases did not show this association for sporadic cancers of the pancreas [13]. The current relationship between the CHEK2 mutation and the occurrence of FPC can be explained by the multiorgan nature of the familial cancer predisposition of CHEK2 mutations. Note that among the FPC cancer cases with detected CHEK2 mutations, there were cases not only with $\mathrm{PaCa}$, but also with cancer of the breast, cervix, thyroid, and melanoma.

Thus far, the possible relationship between CHEK2 mutations and FPC has not been evaluated extensively. In one existing German study based on the genotyping of 35 patients from families with FPC syndrome, the CHEK2 1100delC mutation was identified in one out of 35 FPC cases (3\%) [22]. The authors of that study suggested a possible contribution of the CHEK2 mutation in a small subset of FPC [22]. In addition, it is believed that mutations of the CHEK2 gene, similar to the mutations in the other aforementioned genes, cause only a small percentage of FPC cases. Therefore, it can be assumed, that the search for genes that predispose to FPC, will bring to light new genes, but none of them will be responsible for a large percentage of families with FPC.

Note that mutation carriers with cancer in the present study were affected by cancers at different sites (Supplementary Table 1). Among those, CHEK2 mutation carriers had the largest variety of different neoplasms, i.e., multiple breast cancers, cervical cancers, and single cases of thyroid cancer, $\mathrm{PaCa}$, and malignant melanoma. Each of the two PALB2 mutation carriers had either PaCa or breast cancer. Three $B R C A 1$ carriers with cancer were observed, two of which had breast cancer and one ovarian cancer. These three BRCA1 mutation carriers had no other family member with breast and/or ovarian cancer. A single carrier of the NBS1 mutation was affected by $\mathrm{PaCa}$. The occurrence of $\mathrm{PaCa}$ among the $B R C A 1$ and PALB2 mutation carriers is already known $[14,15]$. The nature of the CHEK2 gene as a multiorgan cancer predisposition gene has been reported [4,5,8-11], which explains the occurrence of cancer at different sites among the CHEK2 mutation carriers in the present study. Despite the single cases of different cancers in these families with $\mathrm{PaCa}$, they only fulfil the criteria for FPC and did not meet the criteria for any other defined inherited tumor syndrome except for three carriers of a BRCA1 mutation (HBOC, BRCA1 type).

Our previous study conducted among $383 \mathrm{PaCa}$ patients reported that the Polish founder mutation in NBS1 (657del5) is associated with an increased risk of $\mathrm{PaCa}(\mathrm{OR}, 3.80$; $\mathrm{p}=0.002$ ) [13]. While the results of the current study, including almost 400 cases from FPC families presented here, did not show a relationship between the NBS1 and FPC syndrome. It might mean that a NBS1 mutation is not associated with the risk of FPC. On the other hand, it is equally possible that a relationship between the NBS1 and FPC risk was not observed because of the relatively small number of cases with cancer $(n=105)$ present in this study, in addition to the low penetrance of NBS1 mutation. Indeed, more cases of cancer from FPC families should be analyzed in the future to resolve this suspicion.

The major limitation of this study was the small number of cases with cancer from FPC families subjected to genotyp- 
ing. These results should be verified with a larger series of FPC cases from both the Polish and other populations.

\section{Conclusion}

This case control study indicated that mutations in PALB2 (172_175delTTGT) appear to increase the risk of FPC in heterozygous carriers from the Polish population. In addition, the FPC risk appears to be increased in carriers of $B R C A 1$ (two of the three occurring: 5382insC, C61G) and CHEK2 founder mutations (particularly CHEK2-I157T missense variant). Therefore, in the Polish population, founder mutations in the genes, BRCA1, PALB2, and CHEK2, cause a small percentage of familial PaCa. Studies in Slavic and other populations should be performed to confirm this association and evaluate the utility of testing these genes for FPC in cancer genetic counselling.

\section{Electronic Supplementary Material}

Supplementary materials are available at Cancer Research and Treatment website (http://www.e-crt.org).

\section{Conflicts of Interest}

Conflict of interest relevant to this article was not reported.

\section{References}

1. Klein AP, Hruban RH, Brune KA, Petersen GM, Goggins M. Familial pancreatic cancer. Cancer J. 2001;7:266-73.

2. MacDermott RP, Kramer P. Adenocarcinoma of the pancreas in four siblings. Gastroenterology. 1973;65:137-9.

3. Lynch HT, Deters CA, Lynch JF, Brand RE. Familial pancreatic carcinoma in Jews. Fam Cancer. 2004;3:233-40.

4. Gorski B, Cybulski C, Huzarski T, Byrski T, Gronwald J, Jakubowska A, et al. Breast cancer predisposing alleles in Poland. Breast Cancer Res Treat. 2005;92:19-24.

5. Cybulski C, Wokolorczyk D, Huzarski T, Byrski T, Gronwald J, Gorski B, et al. A deletion in CHEK2 of 5,395 bp predisposes to breast cancer in Poland. Breast Cancer Res Treat. 2007;102: 119-22.

6. Cybulski C, Kluzniak W, Huzarski T, Wokolorczyk D, Kashyap A, Jakubowska A, et al. Clinical outcomes in women with breast cancer and a PALB2 mutation: a prospective cohort analysis. Lancet Oncol. 2015;16:638-44.

7. Menkiszak J, Gronwald J, Gorski B, Jakubowska A, Huzarski T, Byrski T, et al. Hereditary ovarian cancer in Poland. Int J Cancer. 2003;106:942-5.

8. Cybulski C, Gorski B, Huzarski T, Masojc B, Mierzejewski M, Debniak T, et al. CHEK2 is a multiorgan cancer susceptibility gene. Am J Hum Genet. 2004;75:1131-5.

9. Cybulski C, Wokolorczyk D, Huzarski T, Byrski T, Gronwald $\mathrm{J}$, Gorski B, et al. A large germline deletion in the Chek2 kinase gene is associated with an increased risk of prostate cancer. J Med Genet. 2006;43:863-6.

10. Zlowocka E, Cybulski C, Gorski B, Debniak T, Slojewski M, Wokolorczyk D, et al. Germline mutations in the CHEK2 kinase gene are associated with an increased risk of bladder cancer. Int J Cancer. 2008;122:583-6.

11. Teodorczyk U, Cybulski C, Wokolorczyk D, Jakubowska A, Starzynska T, Lawniczak M, et al. The risk of gastric cancer in carriers of CHEK2 mutations. Fam Cancer. 2013;12:473-8.

12. Cybulski C, Gorski B, Debniak T, Gliniewicz B, Mierzejewski M, Masojc B, et al. NBS1 is a prostate cancer susceptibility gene. Cancer Res. 2004;64:1215-9.

13. Lener MR, Scott RJ, Kluzniak W, Baszuk P, Cybulski C, Wiechowska-Kozlowska A, et al. Do founder mutations characteristic of some cancer sites also predispose to pancreatic cancer? Int J Cancer. 2016;139:601-6.

14. Slater EP, Langer P, Niemczyk E, Strauch K, Butler J, Habbe $\mathrm{N}$, et al. PALB2 mutations in European familial pancreatic cancer families. Clin Genet. 2010;78:490-4.

15. Mocci E, Guillen-Ponce C, Earl J, Marquez M, Solera J, SalazarLopez MT, et al. PanGen-Fam: Spanish registry of hereditary pancreatic cancer. Eur J Cancer. 2015;51:1911-7.

16. Vasen H, Ibrahim I, Ponce CG, Slater EP, Matthai E, Carrato A, et al. Benefit of surveillance for pancreatic cancer in highrisk individuals: outcome of long-term prospective follow-up studies from three European expert centers. J Clin Oncol. 2016;34:2010-9.

17. Zhou BB, Elledge SJ. The DNA damage response: putting checkpoints in perspective. Nature. 2000;408:433-9.

18. Matsuoka S, Huang M, Elledge SJ. Linkage of ATM to cell cycle regulation by the Chk2 protein kinase. Science. 1998;282:1893-7.

19. Vahteristo P, Bartkova J, Eerola H, Syrjakoski K, Ojala S, Kilpivaara $\mathrm{O}$, et al. A CHEK2 genetic variant contributing to a substantial fraction of familial breast cancer. Am J Hum Genet. 
2002;71:432-8.

20. Chehab NH, Malikzay A, Appel M, Halazonetis TD. Chk2/ hCds1 functions as a DNA damage checkpoint in G(1) by stabilizing p53. Genes Dev. 2000;14:278-88.

21. Suchy J, Cybulski C, Wokolorczyk D, Oszurek O, Gorski B,
Debniak T, et al. CHEK2 mutations and HNPCC-related colorectal cancer. Int J Cancer. 2010;126:3005-9.

22. Bartsch DK, Krysewski K, Sina-Frey M, Fendrich V, Rieder H, Langer $\mathrm{P}$, et al. Low frequency of CHEK2 mutations in familial pancreatic cancer. Fam Cancer. 2006;5:305-8. 